\title{
Performance Evaluation of Radiant Cooling System Integrated with Air System under Different Operational Strategies
}

Yasin Khan ${ }^{1}$, Vaibhav Rai Khare ${ }^{1}$ Jyotirmay Mathur $^{1}$, Mahabir Bhandari ${ }^{2}$

${ }^{1}$ Centre for Energy and Environment, Malaviya National Institute of Technology, Jaipur (India) - 302017.

${ }^{2}$ Oak Ridge National Laboratory, Oak Ridge, TN, 37831, USA.

Corresponding author: Mahabir Bhandari, Oak Ridge National Laboratory, Oak Ridge, TN, 37831, USA. Tel: +1 8655740989 ,

email: bhandarims@ornl.gov

Other authors details: Yasin Khan (yasinkhn683@gmail.com), Vaibhav Rai Khare (vrk1007@gmail.com), Jyotirmay Mathur (jyotirmay.mathur@gmail.com)

Notice: This manuscript has been co-authored by UT-Battelle, LLC under Contract No. DE-ACO5O0OR22725 with the U.S. Department of Energy. The United States Government retains and the publisher, by accepting the article for publication, acknowledges that the United States Government retains a non-exclusive, paid-up, irrevocable, world-wide license to publish or reproduce the published form of this manuscript, or allow others to do so, for United States Government purposes. The Department of Energy will provide public access to these results of federally sponsored research in accordance with the DOE Public Access Plan (http://energy.gov/downloads/doe-public-access-plan). 


\begin{abstract}
The paper describes a study developed to estimate the energy savings potential of a radiant cooling system installed in a commercial building in India. To evaluate thermal performance and energy consumption, simulations were carried out using FLUENT and EnergyPlus software, respectively. The building model was calibrated using the measured data for the installed radiant system. Then this calibrated model was used to simulate the energy consumption of a building using a conventional all-air system to determine the proportional energy savings. For proper handling of the latent load, a Dedicated Outside Air System (DOAS) was used as an alternative to Fan Coil Unit (FCU) that was installed in conjunction with the radiant cooling system. A comparison of energy consumption calculated that the radiant system was $17.5 \%$ more efficient than a conventional all-air system and that a $30 \%$ savings was achieved by using a DOAS system compared with a conventional system. The Computational Fluid Dynamics (CFD) simulation showed that a radiant system offers more uniform temperatures, as well as a better mean air temperature range, than a conventional system. To further enhance the energy savings in the radiant system, different operational strategies were analyzed based on thermal analysis using EnergyPlus.
\end{abstract}

Key Words: Radiant Cooling System, Building Energy Simulation, Energy Saving, EnergyPlus, HVAC, CFD. 


\section{Introduction}

There is a growing interest in radiant cooling systems as an energy-efficient approach for building space conditioning. Radiant cooling systems are considered a viable innovative approach. In recent years, much research has been conducted on the energy consumption of radiant systems, and it has been found that a radiant cooling system can reduce electrical energy consumption by approximately $40 \%$ compared with conventional Heating, Ventilation, and Air Conditioning (HVAC) systems [1,2].

In India, conventional all-air systems typically consume $32-55 \%$ of the energy used in a building, depending on the building type and operating hours [3]. A significant part of electric energy is consumed by the fan which is used to transport the cool air as heat transfer medium in the conditioned space. In radiant cooling system temperature of the structure is reduced by supplying chilled water at higher temperature flowing through the pipes embedded in the structure. This increases the radiant heat transfer from the human body and that heat is taken away by the flowing chilled water temperature. The radiant cooling system removes the major part of the sensible load while latent load and remaining sensible load is removed by the ventilation system. Therefore, the radiant cooling system separates the thermal conditioning and ventilation task which results in the significant reduction in the HVAC energy consumption (4-6). In addition, an integrated radiant cooling system treats the cooling load individually and more uniformly and thus improves thermal comfort [7].

Henze et al. [8] analyzed buildings with Thermo Active Building Systems (One of the type of radiant cooling system). The analysis showed better thermal comfort with low energy consumption, about $20 \%$ less, when compared to all-air VAV system. Stetiu [9] describes the parametric study for radiant cooling system in commercial buildings for different location of United States of America through numerical modeling. The results show that the radiant cooling system can save on average $30 \%$ of the energy consumption and $27 \%$ of the peak power demand over a traditional all-air system. Oxizidis and Papadopoulos [10] compared radiant and convective systems with respect to energy consumption and thermal comfort in a test cell representing an office room by carrying out computer simulations of a single office in in warm and humid climates. that the simulation study showed that the FCU is consuming more than $14 \%$ more primary cooling energy with respect to the radiant systems. Niu et al. [11] evaluated the system performance and energy saving potential of a radiant cooling system with desiccant cooling through energy simulation and result indicated that chilled ceiling combined with desiccant cooling could save up to 
$44 \%$ of the primary energy consumption, in comparison with conventional constant volume all-air system. Sodec [12] compared the energy cost of a VAV and a cooling ceiling system using a numerical simulation program TRNSYS. From a specific cooling load of 45 to $55 \mathrm{~W} / \mathrm{m} 2$, the first costs of the cooling ceiling system can be well below those for the VAV system up to $20 \%$.

The studies cited above demonstrate that the radiant cooling systems have a potential to save signification energy as compared to the conventional all air systems. However, the performance of the radiant cooling system is depend on the climatic condition; like the use of radiant cooling system in hot and humid climate is very critical because of condensation problem [13-14]. A simulation-based study demonstrated that a radiant slab system provided 10 to $40 \%$ better energy performance than a conventional system, depending on the climate type. The best performance was achieved in dry climates [15].

The radiant cooling system in itself, because of its design limitations, does not address the latent load of the conditioned area; as a result, condensation may occur on the cooling surface, depending on the prevailing environmental conditions. However, add-on supplemental systems can be deployed to overcome this disadvantage [16]. To prevent condensation, additional dew point temperature control of the conditioned space using a parallel ventilation system is needed to maintain indoor air quality [17].

Previous studies show that many simulation studies have been performed globally for radiant system technology. In India, radiant systems are not fully understood because they do not cater the latent heat demand. The design of a radiant system is complicated because of the coupling between thermal load, building structure, and hydronic system and its impact on thermal comfort [18-20]. Even experienced professionals acknowledge the complications in radiant system design and integration. This study describes the integration of a radiant system with other technologies to cater the latent load. The calibrated simulation model approach is used in this paper to analyze the performance of radiant cooling system alongwith the integration of technologies to provide the latent loads and outside air.

Building energy simulation tool model the energy performance of the building, but well mixed air approximation is limitation of this type of modeling because air temperature is not uniform throughout any specific location in the space. The non-uniform temperature distribution could increase the thermal discomfort of the occupants. CFD simulation can provide detailed thermal environment and contaminant information. In recent years, CFD has become a more reliable tool for the evaluation of indoor thermal comfort and air quality. However, the application 
of CFD to real building design has been limited as it requires excessive computer resources and long running time. [21]. However, complex and less common systems such as radiant cooling systems could benefit from the detailed CFD simulations in order to gain the confidence in the ability of these system in providing better thermal comfort. This paper demonstrates the use of CFD modeling to analyze the radiant cooling system for thermal comfort analysis.

\section{Evaluation Approach}

The main objectives of this paper are to (1) evaluate the energy savings achieved by a radiant cooling system installed in an existing IT company building compared with a conventional all-air HVAC system and (2) use simulation to study possible enhancements of its performance, from both the energy and thermal environment perspectives. To meet these objectives, building models were developed in EnergyPlus and ANSYS FLUENT software, respectively. Three energy models of the buildings were developed in EnergyPlus. The building energy models in this paper are referred as follows:

- the existing radiant system - "Running Case,"

- the hypothetical conventional HVAC system -"Conventional Case," and

- the radiant system with additional energy-saving options - "Advanced Case."

The Running Case represents the existing radiant system in the building, which is coupled to FCUs to cater the latent heat load. This model, calibrated with the measured data, was simulated for energy performance. Then the same cooling load was applied for the Conventional Case, which represents an auto-sized conventional central cooling system. The objective of the calibration was to apply identical cooling loads on the Conventional Case and the Running Case to make a reasonable comparison. To enhance the energy savings in the existing building, the Running Case was modified by replacing the FCUs with a DOAS coupled with an Energy Recovery Wheel (ERW). In this Advanced Case, deficiencies in the radiant cooling system were eliminated. To further improve energy efficiency, different operational strategies were analyzed based on thermal analysis. The whole methodology is shown in Figure 1. 


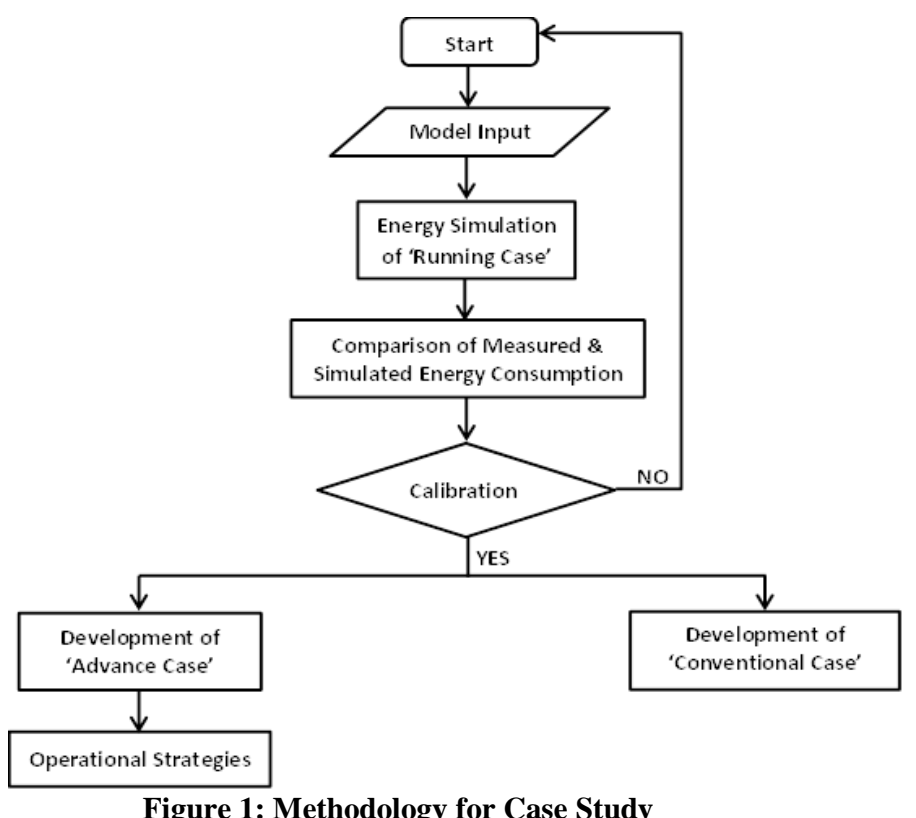

Figure 1: Methodology for Case Study

Computational Fluid Dynamics (CFD) tools were used to capture spatial and temporal variations in the flow and thermal properties for specified boundary condition. To evaluate indoor air quality and thermal comfort, CFD simulations were conducted for the Running Case and the Conventional Case. The CFD model was validated with the energy model of the building. The energy analysis was done using the EnergyPlus v8.0 [22] program, and thermal performance was evaluated using the CFD software ANSYS FLUENT v14.5 [23], which can effectively model and analyze heat transfer applications. Thermal modelling of HVAC system was performed using EnergyPlus and the CFD modeling was used for simulating the effect of air and temperature distribution. For the CFD analysis, the boundary conditions were collected from EnergyPlus simulated data with taking hourly radiant floor and ceiling temperature constant as an assumption.

\section{Building Modeling}

This section discusses the methodology followed to develop the three cases for simulation and explains the input parameters required for modeling.

\subsection{Development of the Running Case Model}

\subsubsection{Building Description}


The modeled building is an IT office building of the company Tech Mahindra located in Hyderabad, India, in a composite climatic zone [24]. It has a conditioned space of approximately $354 \mathrm{~m}^{2}$. Figure 2 shows a schematic of the building geometry and HVAC system configuration. There are two chillers for the production of cold water. One chiller, with a capacity of $12 \mathrm{TR}$ (tones of refrigeration) was installed for the radiant cooling system. The other is a large, old chiller with 100TR capacity that provides chilled water to the FCU cooling coils. The old chiller is also integrated with the space-conditioning system in another adjacent building to provide chilled water.

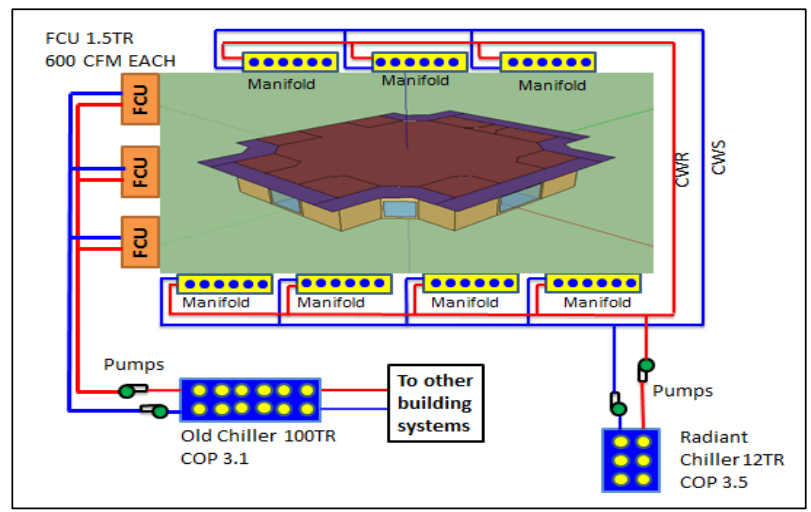

Figure 2: System Configuration

The simulations considered a variable-occupancy pattern in the range of 10 to 50 persons and office hours from 7 a.m. to 7 p.m. on weekdays. No weekend occupancy was considered. Based on the ASHRAE Handbook [25], each occupant was considered to generate $115 \mathrm{~W}$ of heat, of which $70 \mathrm{~W}$ was sensible and $45 \mathrm{~W}$ was latent load. The other building construction and operation related parameters are shown in Table 1.

Table 1 Building input parameters

\begin{tabular}{|c|c|}
\hline Building input parameters & Value \\
\hline Wall construction & $\begin{array}{l}\text { Brick wall with both sides consisting of cement plaster } \\
\text { (U-factor with film }\left[\mathrm{W} / \mathrm{m}^{2} \cdot \mathrm{K}\right]=1.87 \text { ) }\end{array}$ \\
\hline Roof construction & $\begin{array}{l}\text { Concrete roof with outside cement plaster and inside gypsum } \\
\text { plaster (U-factor with film }\left[\mathrm{W} / \mathrm{m}^{2} \cdot \mathrm{K}\right]=1.054 \text { ) }\end{array}$ \\
\hline Floor construction & $\begin{array}{l}\text { Layer by layer as hard stone + EPS + screed+ floor tiles } \\
\left(\mathrm{U}-\text { factor with film }\left[\mathrm{W} / \mathrm{m}^{2} \cdot \mathrm{K}\right]=0.962\right)\end{array}$ \\
\hline Window material glazing & SHGC $=0.61$, conductivity $=5.71, \mathrm{VLT}=0.88$ \\
\hline Window frames and dividers & Painted wooden window frame with divided lite type divider \\
\hline Window-wall ratio & $\begin{array}{l}\mathrm{E}=11.7 \%, \mathrm{~W}=0 \%, \mathrm{~N}=0 \%, \mathrm{~S}=20 \% \\
\text { Building average }=8.02 \%\end{array}$ \\
\hline Overhang & 2 meter \\
\hline $\mathrm{LPD}\left[\mathrm{W} / \mathrm{m}^{2}\right]$ & 8.5 \\
\hline Plug load $\left[\mathrm{W} / \mathrm{m}^{2}\right]$ & 20 \\
\hline Occupancy & 50 \\
\hline
\end{tabular}




\subsubsection{HVAC System Configuration}

The radiant cooling system includes both floor and roof versions (Figure 3 and Figure 4, respectively), which are integrated in the slab and cater to sensible cooling loads.

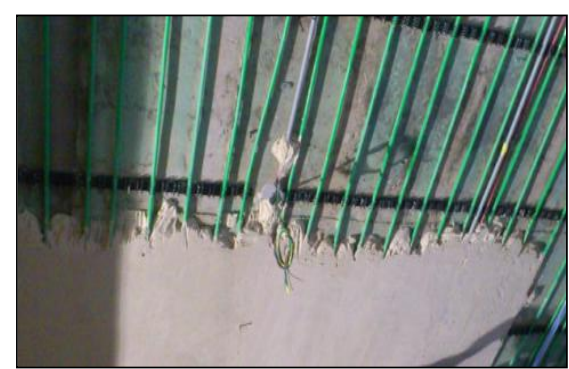

Figure 3: Radiant ceiling cooling system

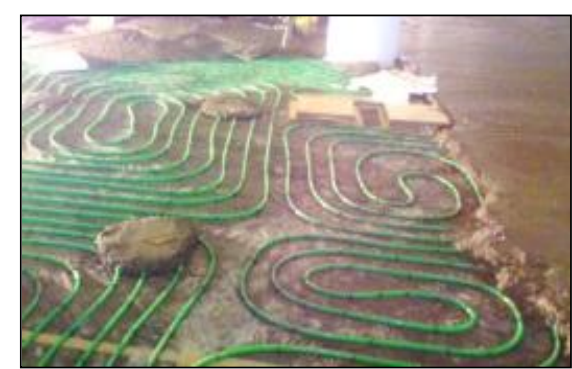

Figure 4: Radiant floor cooling system

For latent loads, FCUs are provided which are coupled to an air-cooled chiller. This chiller mainly provides cooling for an adjacent building, besides supplying chilled water to the FCUs in this building. The ventilation is thus provided by a constant-volume FCU system functioning with $20 \%$ outside air only. For modeling purposes, the FCU chiller was auto-sized for its given Coefficient of Performance (COP) because it is coupled with another building. The zone thermostat controls operation of FCU system, and the radiant set point temperature determines the response of the radiant system by varying the chilled water flow rate [12]. The fan pressure rise, fan efficiency, and motor efficiency are taken as $330 \mathrm{~Pa}, 52 \%$, and $80 \%$ respectively [26]. A detailed description of the HVAC system configuration is given in Table 2 . 
Table 2 HVAC system configuration parameters

\begin{tabular}{l|l}
\hline \multicolumn{1}{c|}{ Parameter } & \multicolumn{1}{c}{ Value } \\
\hline HVAC system type & Radiant floor and ceiling system with FCU \\
\hline Fan design & Constant volume with $0.85 \mathrm{~m}^{3} / \mathrm{s}(1,800 \mathrm{CFM})$ \\
\hline Supply air temp set point & $19-20^{\circ} \mathrm{C}$ \\
\hline Chiller parameters & $\begin{array}{l}\text { FCU chiller auto-sized with } 3.1 \mathrm{COP} \text { and } 12^{\circ} \mathrm{C} \text { leaving chilled } \\
\text { water temperature } \\
\text { Radiant chiller } 12 \mathrm{TR} \text { with } 3.5 \mathrm{COP} \text { and } 16^{\circ} \mathrm{C} \text { leaving chilled water } \\
\text { temperature }\end{array}$ \\
\hline $\begin{array}{l}\text { Radiant pipe diameter, } \\
\text { spacing, and loop length }\end{array}$ & $\begin{array}{l}\text { Diameter }=15 \mathrm{~mm} \\
\text { Spacing }=150 \mathrm{~mm} \text { in ceiling, } 100 \mathrm{~mm} \text { in floor } \\
\text { Loop length }=4,640 \mathrm{~m}\end{array}$ \\
\hline Ventilation & $20 \%$ fresh air of the total supply flow \\
\hline Zone set point temp & $24^{\circ} \mathrm{C}$ \\
\hline Building Operation Schedule & $7 \mathrm{AM}$ to $7 \mathrm{PM}$ \\
\hline
\end{tabular}

\subsection{Model Calibration and Validation}

The general purpose of model calibration is to achieve more accurate simulation results that can match the measured data within good agreement. The US Department of Energy's Federal Energy Management Program (FEMP) measurement and verification guidelines [27] provide some criteria for the calibration in the NMBE (Normalized Mean Bias Error) and CvRMSE (Coefficient of Variation of Root Mean Square Error) indexes.

The measured data included only the cooling energy of the chiller, as this study was concerned only with cooling energy consumption. Therefore, this paper discusses only the cooling energy use of the building, based on the availability of data. Calibration was done by adjusting the occupancy and plug load (electrical equipment) patterns, which have the highest diversity to match the measured and simulated HVAC energy consumption on an hourly basis from April through June. A mapping of measured and simulated thermal cooling energy consumption is shown in Figure 5.

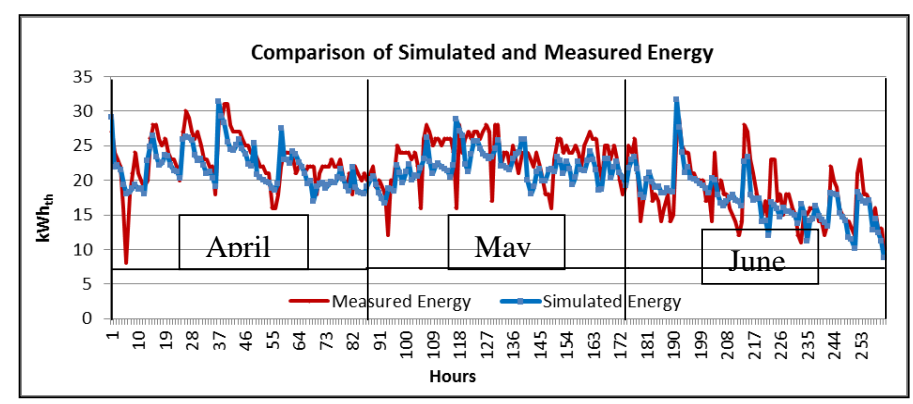

Figure 5: Comparison of Simulated and Measured Energy 
The calibration results were found to be well within the acceptable limits of the NMBE and CvRMSE criteria and thus are satisfactory. Acceptable annual tolerances for NMBE and CvRMSE (FEMP, International Performance Measurement and Verification Protocol) are listed in Table 3. The calibrated model can, therefore, be used with confidence for the energy savings calculations.

Table 3 Calibration Criteria

\begin{tabular}{c|c|c|c|c}
\hline \multirow{2}{*}{$\begin{array}{c}\text { Calibration } \\
\text { type }\end{array}$} & \multirow{2}{*}{ Index } & \multicolumn{2}{|c|}{ Limit } & \multirow{2}{*}{$\begin{array}{c}\text { Calibrated } \\
\text { model error }\end{array}$} \\
\cline { 3 - 4 } & (IPMVP) & (FEMP) & $4.7 \%$ \\
\cline { 3 - 4 } Hourly & MBE & - & $\pm 10 \%$ & $13.5 \%$ \\
\cline { 2 - 4 } & CvRMSE & $\mathbf{2 0 \%}$ & $30 \%$ & 4.5 \\
\hline
\end{tabular}

\subsection{Development of the Conventional Case Model}

To calculate the energy savings of the existing radiant cooling system, a Conventional Case was modeled in which the building construction and operational parameters remained the same but the existing radiant cooling system was replaced by a central cooling system. To provide sufficient cooling, the supply air temperature was reduced to $12-$ $14^{\circ} \mathrm{C}$ and the air system was switched to auto-sized mode to maintain the desired setpoint temperatures in the occupied areas. Fan design conditions were modified, as the entire cooling load was handled by cooled air, making a higher supply air flow necessary. Chiller operating parameters were kept the same because the air-cooled chiller described in Table 2 was used, which also provides chilled water to the adjacent building. The schematic for the conventional Case is shown in Figure 6.

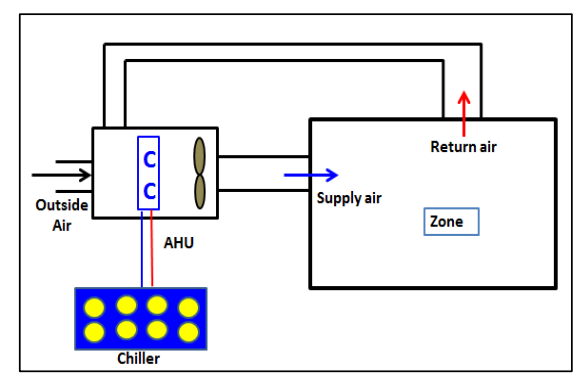

Figure 6: Schematic of Conventional Case

\subsection{Development of CFD Model}

In this analysis, the geometry of the flow domain was modeled keeping all the geometrical parameters same as in existing building using ANSYS's workbench platform i.e. ANSYS's DESIGN MODELER. Developed physical model of building was meshed using 3D hexahedral meshing comprised of total 3, 32,852 cells respectively in ANSYS's workbench MESHING. The building geometry and meshed drawing are shown in Figure 7. 


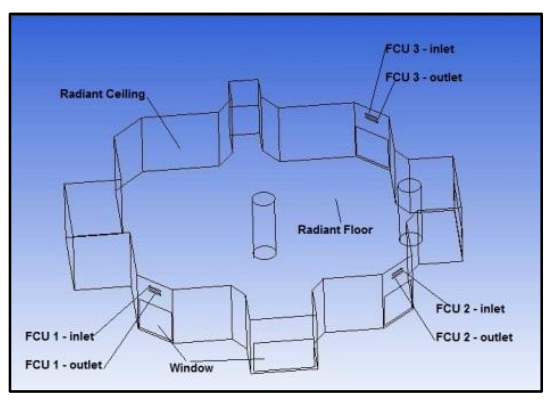

(a) Drawing of Building

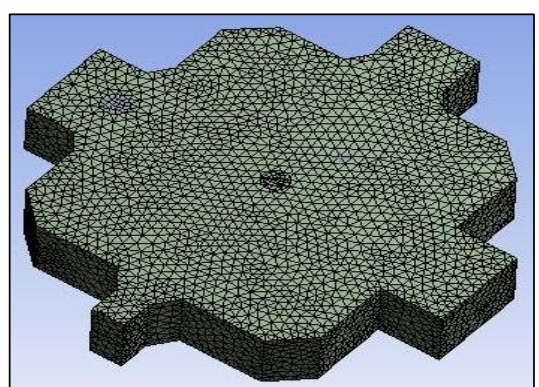

(b) Meshed Drawing of building

Figure 7: CFD Drawing of Building

A numerical solution was carried out with an unsteady state implicit pressure-based solver using ANSYS FLUENT v 14.5 which uses finite volume method to convert the governing equations to numerically solvable algebraic equations. Boundary conditions play a crucial role in CFD analysis. Internal boundary conditions for an internal analysis relate to the wall and window surface temperatures, surface boundary condition of supply diffusers, blocks and assemblies etc. Building have both ceiling and floor radiant system installed in it so initial radiant floor and ceiling temperatures were taken from EnergyPlus output of the calibrated model.

For the flow from the FCUs, a "mass flow inlet" boundary condition was specified in which the inlet air temperature was the total air temperature i.e. sums of re-circulated air and ambient air temperature. The temperatures of radiant ceiling, floor and mass flow rate of FCU were varied at an interval of 1 hour according to the EnergyPlus result using PROFILE function, and for the return air supply duct, a "pressure-outlet" condition was specified. As the air flow was expected to be turbulent, a k- $\square$ model was considered for the turbulence model. The k- $\square$ standard model is a model based on model transport equations for the turbulence kinetic energy $(\mathrm{k})$ and its dissipation rate ( $\square$ ). The $\mathrm{k}-\square$ model is commonly used in most CFD programs for building [28]. This model is useful as the requirements of computer hardware are not so demanding and applicable for a wide range of flows. The k- $\square$ model would not give results much different from those predicted by more complicated models with second order correction; nor with combination of models [29]. A Surface-to-Surface radiation model was used for radiation heat transfer from the building walls. The surface-to-surface radiation model can be used to account for the radiation exchange in an enclosure of surfaces i.e. walls. Physical and thermal properties of the different engineering materials were used, according to the material types. 


\subsubsection{CFD Model Validation}

For model calibration, hourly readings for the floor temperature, roof temperature, supply air temperature, and the mass air flow rate of the FCUs were taken from the EnergyPlus model—typically for the simulation done for April 09, 2013, from 8 a.m. to 7 p.m. and applied to both of the alternatives for CFD validation. It was assumed that for an hour, the temperature does not vary so a temperature profile has been created for each of the parameter and simulation was done with the help of FLUENT.

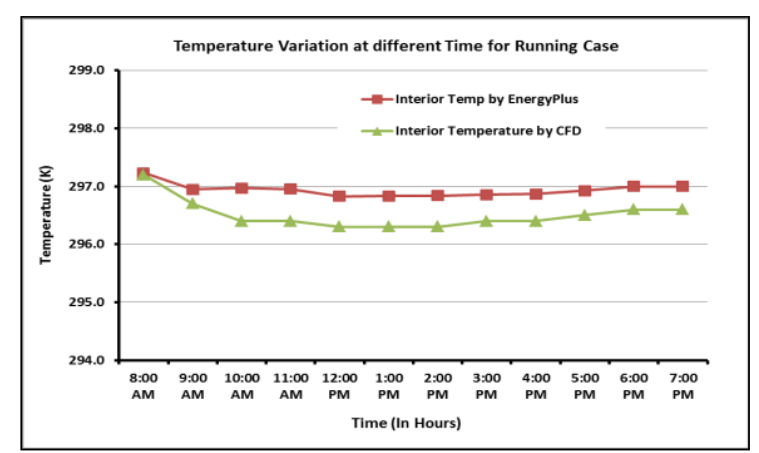

Figure 8: Temperature Variance (Running Case)

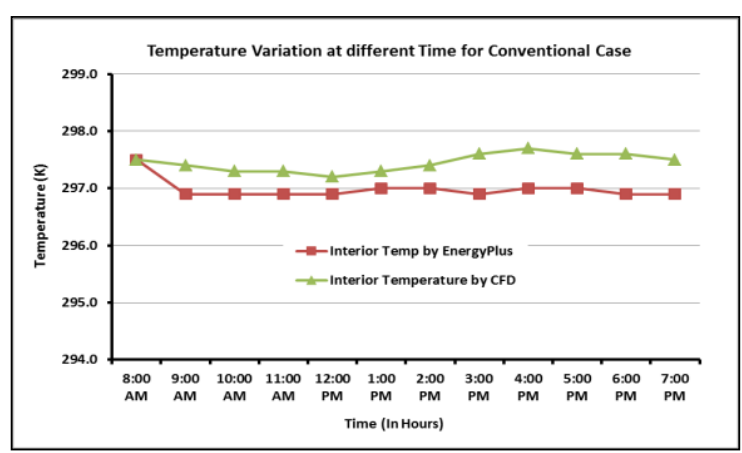

Figure 9: Temperature Variance (Conventional Case)

It was observed that the variation in the simulated results for air temperature in the CFD model and in EnergyPlus are in good agreement, as shown in Figure 8 and Figure 9. The marginal difference between the temperatures can be credited to load-dependent flow temperature variations. The CFD model can thus be considered a validated model for further performance analysis.

\subsection{Development of the Advanced Case}

In radiant cooling, condensation occurs with changes in floor surface temperature, room air temperature, and room air humidity. It occurs when the cooling surface temperature is equal to or below the dew point temperature because the dehumidification capacity of the FCUs is inadequate. FCUs are mainly for handling sensible cooling load, not latent load, so the appropriate level of dehumidification did not occur and the zone dew point fell below the cooling surface temperature. To handle the problem of condensation on the cooling surface, a separate constant-volume DOAS was modeled and integrated with the existing radiant cooling system to provide the minimum amount of ventilation air required by ASHRAE Standard 62 [30]. The integrated system also included an ERW. To maintain the lower dew point temperature in the zone, the model assumed the outdoor air was dehumidified before entering 
the space, and the supply air flow rate just met the ventilation requirement. All other operating and constructionrelated parameters were set the same as in the Running Case. The schematic is shown in Figure 10.

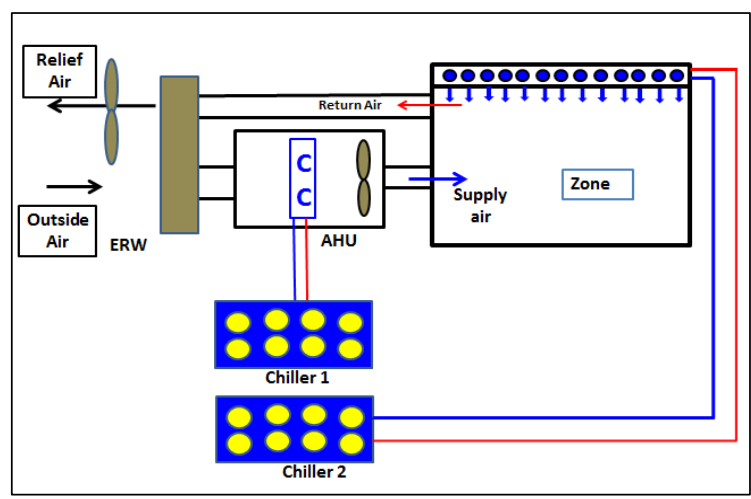

Figure 10: Schematic of Radiant System with DOAS

\section{Results and Discussion}

One of the objectives of this paper was to simulate the performance of HVAC system modifications and compare the performance with the simulated conventional case. To compare the energy consumption of the different cases, hourly annual simulations were conducted using Typical Meteorological Year (TMY) weather data for the Hyderabad, India. However, as the measured data for the buildings were available only for April through June, the calibration study was carried out only for this period. The following sections provide detailed descriptions of energy consumption in the different cases and energy savings of Running and Advanced cases as compared to the Conventional case.

\subsection{Monthly Energy Consumption Comparison of Running and Conventional Case}

Figure 11 shows the energy savings for the Running Case compared to the Conventional case along with the outdoor dry bulb temperature (DBT) and relative humidity (RH). In March through May, when the outdoor DBT increased, the energy savings due to the Running Case also increased because the response of the radiant cooling system increased. After May, when the outdoor RH increased, the performance of the radiant system declined because the radiant system could not cater the latent load. Therefore, the energy savings of the Running Case compared with a Conventional case declined. The highest energy savings (29.5\%) was achieved in May when the 
outdoor environment was somewhat hot and dry, a favorable conditions for the radiant cooling system used in the Running Case.

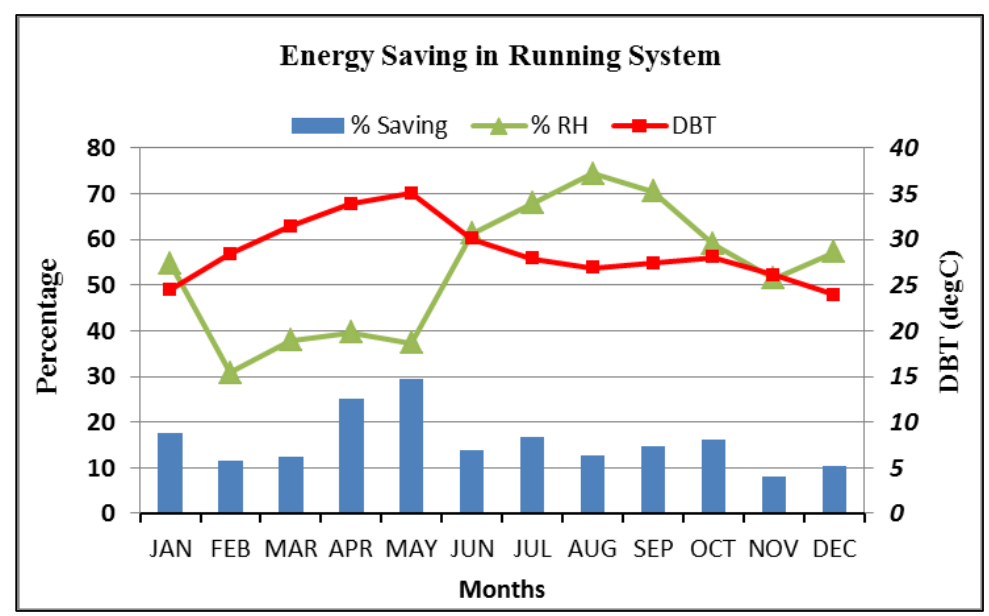

Figure 11: Energy savings for Running Case over Conventional Case

\subsection{Monthly Energy Consumption Comparison of Advanced Case and Conventional Case}

Error! Reference source not found. shows the energy savings of Advanced case as compared to the Conventional case. The figure shows that from June to September, when the outdoor RH was high, the performance of the DOAS integrated system declined because the DOAS had to work more in the humid season. However, the savings for the Advanced Case were higher than for the Running Case because the DOAS catered the latent load more efficiently than did the FCUs. So the energy savings in each month were higher for the Advanced Case than for the Running case. The maximum energy savings for the Advanced Case, $37.8 \%$, was achieved in May, compared with a $29.5 \%$ savings for the Running Case — almost $8 \%$ more energy saved in the Advanced Case. The average energy savings in the humid season for the Advanced Case was 32.5\%, compared with only $16 \%$ for the Running Case. The advanced case shows the consistent savings throughout the year.

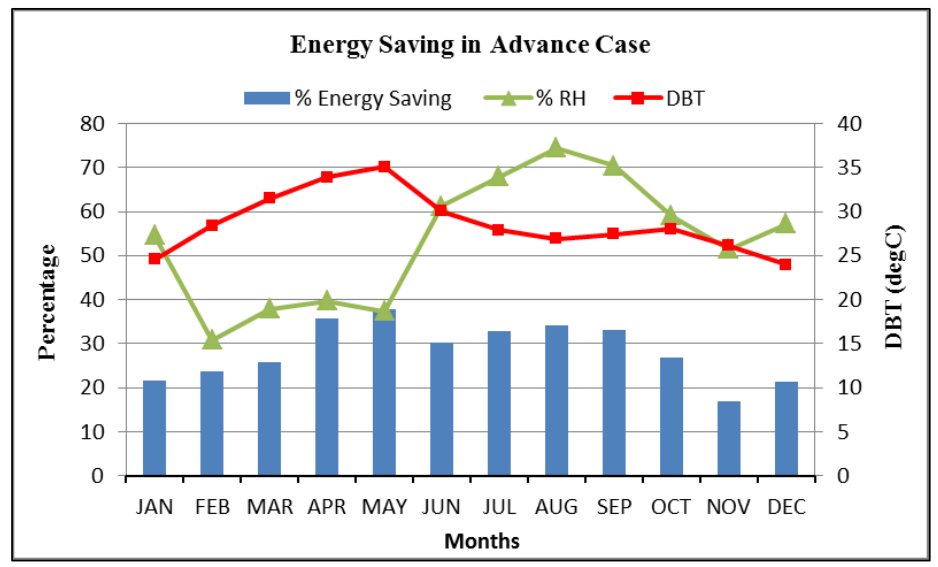


Figure 12: Energy Saving in Advanced Case over Conventional Case

\subsection{Annual Energy Consumption Analysis}

All three cases were simulated for annual HVAC system and components energy use. The annual energy consumption was analyzed for all three cases. Figure 13 shows the annual energy consumption breakdown of HVAC system components for all three cases.

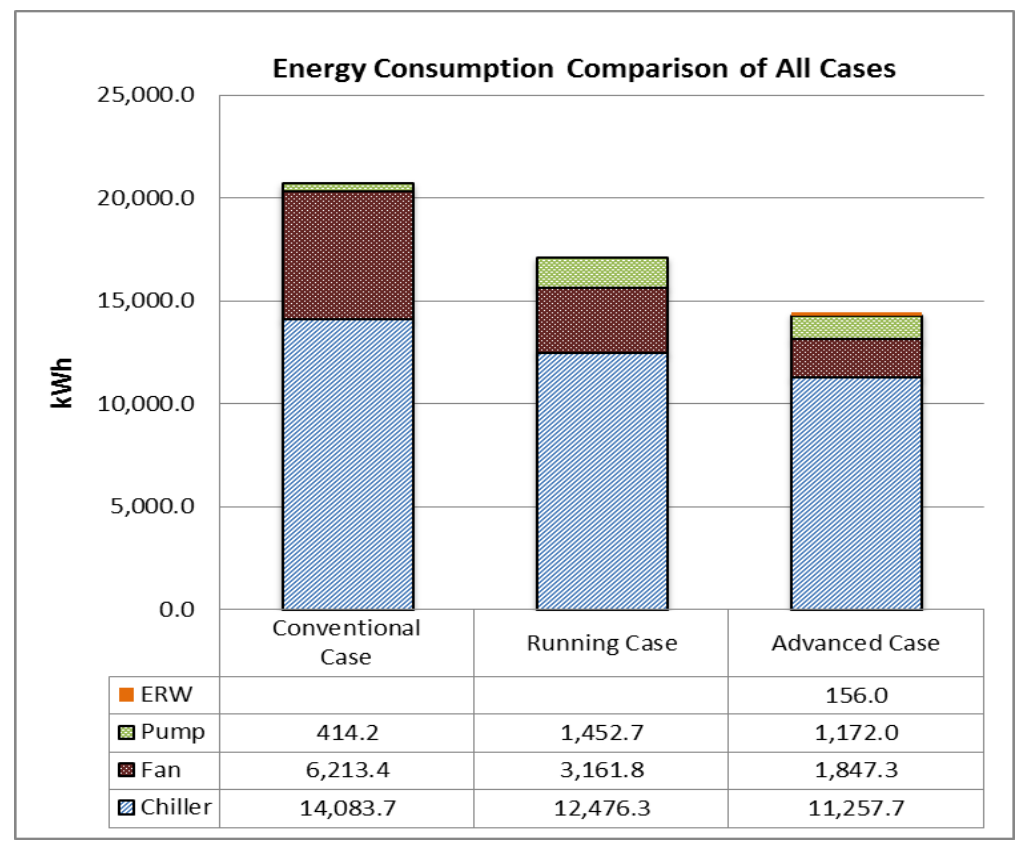

Figure 13: Annual Energy Consumption of all Cases

It can be observed from the analysis of Figure 13 that:

- The radiant system integrated with FCU (Running case) and the radiant system integrated with a DOAS (Advanced case) achieved $17.5 \%$ and $30.3 \%$ energy savings over the Conventional Case respectively. The energy savings were mainly due to the reduced fan energy consumption in the FCUs and the DOAS, which amounted to about $50 \%$ and $30 \%$ respectively of the fan energy used in the Conventional Case. The reason for reduced fan power is that the cooling was provided mainly by chilled water, which reduces the air flow requirement and thus decreases the fan energy use.

- Similarly, the chiller energy consumption in the Running Case dropped by $11.5 \%$ compared with the Conventional Case, because the main cooling load was handled by the radiant system rather than by the cool 
supply air. Thus the radiant system was more efficient than the Conventional Case. Chiller energy consumption in the Advanced Case was 9\% less than in the Running Case because of the ERW. The reduced supply air flow rate may also be a reason, but it does not play a major role.

- The energy used for pumping water in the Running Case was 3.5 times that in the Conventional Case, but the increase in pumping energy was only $34 \%$ of the fan energy savings.

\subsection{Temperature distribution analysis}

Besides the energy savings described above, the temperature distribution in the room was simulated using the validated CFD models. A building simulation was run for both scenarios (Running Case and Conventional Case) to ascertain the spatial distribution of indoor air temperatures at variable room heights and the mean air temperature of the zone for a day.

As shown in Figure 14, the radiant cooling system (Running case), both the roof and the floor versions, delivered uniform spatial indoor air temperatures at various heights. The Conventional Case, in comparison, delivered nonuniform temperatures at different heights. This is mainly because for conventional case the cooling source i.e. FCU are installed at certain elevation in conditioned area and the heat gain is occurred from ceiling as well as roof which creates a non-uniform temperature distribution. While in the Running case, cooling sources are both FCU and radiant cooling system. The lower air movement in this case causes more uniform temperature.
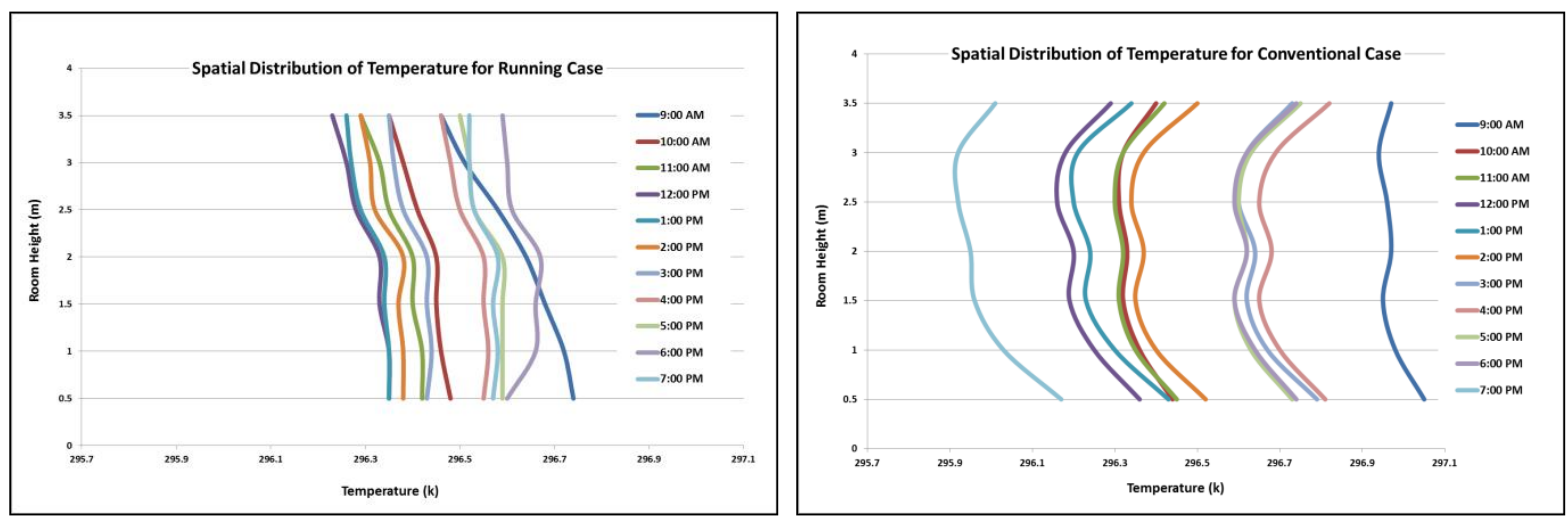

Figure 14: Spatial temperature Variance for Running Case \& Conventional Case

The mean air temperature range for the Running Case and Conventional Case scenarios was computed by averaging the temperatures of the zone at different increments of time. The Running Case (Figure 15) had a higher percentage 
of time at the mean air temperature and less fluctuation in mean air temperatures, an important factor in good thermal comfort conditions.

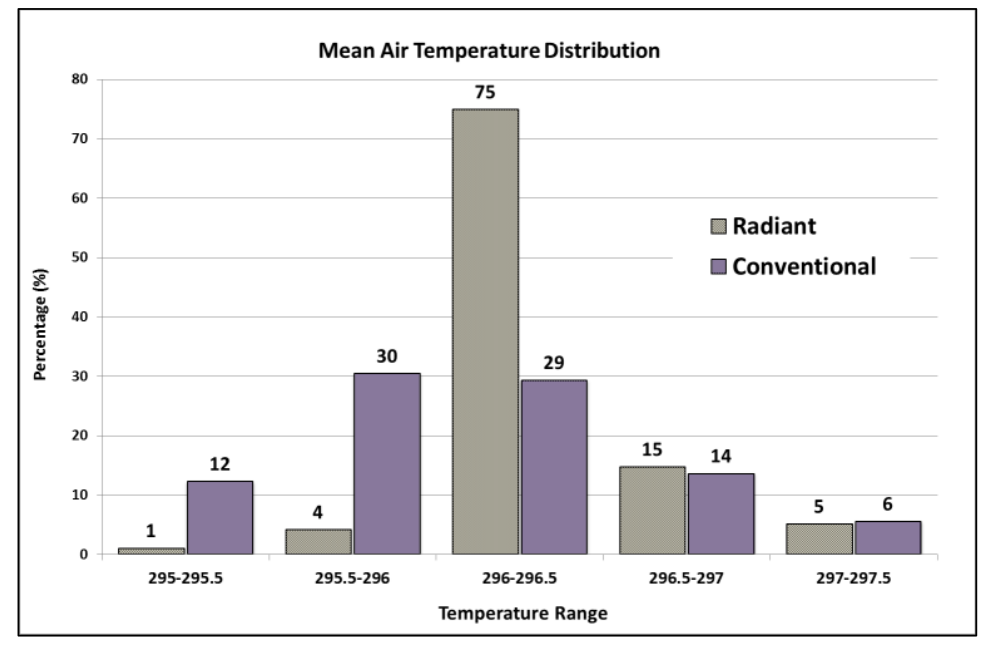

Figure 15: Average air temperature distribution

\section{Future Energy Enhancement Options}

One of the objectives of this paper was to explore the energy savings measures using validated simulation models.

This section describes a study of various control concepts, based on computer simulations, to explore further energy savings. The results show that a combination of time based controls of system would provide acceptable indoor conditions and lower energy consumption. Several ASHRAE studies on real and experimental buildings found that cooling energy savings could be achieved by taking advantage of building thermal mass, but this approach requires an optimized system control strategy tailored to the building and location [31].

Architecture can significantly affect building energy performance and occupant comfort. Heavy-mass materials such as stone, brick masonry, and concrete have long been used in building construction. These materials have physical properties that enable them to naturally store thermal energy and buffer dynamic heat transfer interactions in their immediate environment. The purpose of this portion of the study was to investigate whether thermal mass can maintain the internal environment of a building, resulting in lower energy requirements from the mechanical systems. 
Two control methods were considered in the study. One is time of operation, which studies the effect of thermal mass by shutting down the radiant system before its scheduled shutdown time. Four different system shutdown schedules were considered. The second approach is intermittent operation of the circulation pump [32]—operating the pump intermittently to save electrical energy. The heat in the slab will continue to flow toward the cooler center while the pump is shut down. When the pump is started again, it will be operating with a larger temperature difference between the water and the concrete and so will remove more of the stored heat in a shorter time. Three different pump shutdown schedules were followed for analysis. All of the cases—-four system shutdown schedules and three pump shutdown schedules—are shown in Table 4.

\section{Table 4: Calibration Criteria}

\begin{tabular}{l|l}
\hline Case \# & \multicolumn{1}{c}{ Description } \\
\hline Case 1 & Radiant system off before 1 hour to its original scheduled time \\
\hline Case 2 & Radiant system off before 2 hours to its original scheduled time \\
\hline Case 3 & Radiant system off before 3 hours to its original scheduled time \\
\hline Case 4 & Radiant system off before 4 hours to its original scheduled time \\
\hline Case 5 & Pump on for 2 hours and off for 1 hour \\
\hline Case 6 & Pump on for 1 hour and off for 1 hour \\
\hline Case 7 & Pump on for $1 / 2$ hour and off for $1 / 2$ hour \\
\hline
\end{tabular}

These seven cases were analyzed for their respective energy consumption and for unmet hours (hours when HVAC system is unable to provide the zone set point temperatures), as specified in ASHRAE Standard 90.1 [33]. The maximum energy savings was achieved in case 7, but the total unmet hours were also very high in that case; so its energy savings could not be compared with those in the other cases with fewer unmet hours. It can be concluded that the schedule in case 4 can be used to enhance energy saving, as the unmet hours were very low and energy savings of $>10 \%$ can be achieved. Figure 16 shows the energy savings of different cases compared with unmet hours. 


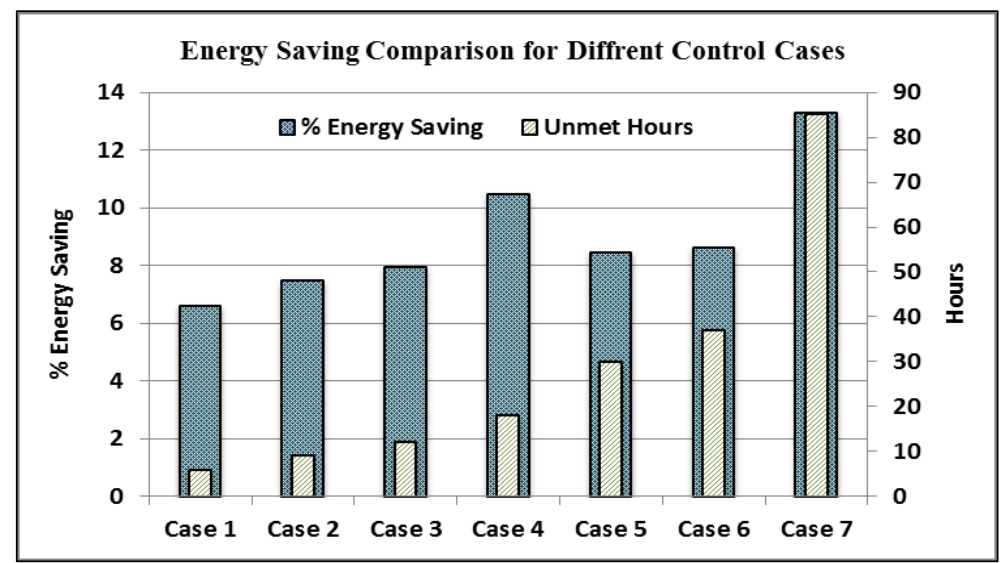

Figure 16: Energy Saving Comparison for Different Control cases

\section{Conclusions}

HVAC systems in buildings are recognized as being the building component that consumes the most energy. The radiant cooling system has inherent energy-saving design features that improve its energy performance compared with conventional space-conditioning systems. This study was carried out to ascertain the energy performance of a radiant cooling system, using simulation tools, for an IT office building at Tech Mahindra in Hyderabad and then extend the analysis to further optimize the system with feasible energy-efficiency alternatives. An existing cooling setup consisting of an integrated radiant cooling system and FCUs, termed the Running Case, was modeled to assess the energy performance. The results were validated with the actual energy consumption data. This validated model was used to simulate the energy consumption of a building using a conventional all-air cooling system, termed the Conventional Case, to determine the energy savings of the radiant system. The following is a summary of the simulation results:

- In terms of energy consumption, the analysis showed the Running Case is $17.5 \%$ more efficient than the Conventional Case. The energy savings varied when compared on a monthly basis because of the dependence of energy consumption on the normal outdoor weather conditions. It was observed that when the outdoor RH was lower and the DBT was higher in April and May, the energy savings were around 30\% and 25\%, respectively—higher than in the high-humidity season.

- To overcome condensation problems, an Advanced Case was considered in which the FCUs of the existing radiant system were replaced with a DOAS to provide $100 \%$ outdoor air to satisfy ventilation and dehumidification requirements. The condensation occurred on the cooling coil of the DOAS, and the cool 
supply air thus reduced the dew point temperature in the conditioned space. The Advanced Case produced the largest energy savings—-approximately $30 \%$ compared with the Conventional Case.

- CFD simulation also was performed to evaluate indoor air quality and thermal comfort. The radiant cooling system maintained uniform, stable indoor air temperatures in the zone. Therefore, the radiant cooling system achieved better thermal performance while consuming less energy than a conventional cooling system.

- After the energy performance analysis, dynamic control simulations were conducted to explore approaches to further enhance energy savings. Based on a thermal mass property of various construction materials, several cases with incremental operational differences were short-listed for a comprehensive analysis. It was found that the maximum energy savings was achieved, and the unmet hours were well within limits, in case 4 , in which the radiant system was shut off before 4 hours. The energy savings achieved in this case was more than $10 \%$ over the savings in the Advanced Case.

The study shows greater energy savings opportunities when a radiant cooling system is integrated with a DOAS and operational control strategies are used. Further research should be considered on the possible use of low-heatrejection systems such as evaporative cooling, ground source heat pumps, and cooling towers with heat exchangers. 


\section{Acknowledgements}

We acknowledge financial support provided by the Department of Science and Technology, Government of India, under the US-India Centre for Building Energy Research and Development (CBERD) project. The authors also acknowledge Mr. R. Madhusudhan Rao, Oorja Energy Engg. Services Hyd. Pvt. Ltd., for providing metered energy use data and Mr. Damodhar Reddy, Tech Mahindra, for supporting the study. Funding for this project was partially provided by field work proposal CEBT105 under the Department of Energy Building Technology Activity Number BT0201000.

\section{Disclaimer}

This paper was partially prepared as an account of work sponsored by an agency of the United States Government. Neither the United States Government nor any agency thereof, nor any of their employees, makes any warranty, express or implied, or assumes any legal liability or responsibility for the accuracy, completeness, or usefulness of any information, apparatus, product, or process disclosed, or represents that its use would not infringe privately owned rights. Reference herein to any specific commercial product, process, or service by trade name, trademark, manufacturer, or otherwise, does not necessarily constitute or imply its endorsement, recommendation, or favoring by the United States Government or any agency thereof. The views and opinions of authors expressed herein do not necessarily state or reflect those of the United States Government or any agency thereof. 


\section{References}

1. R.D. Watson, K. S. Chapman. Radiant Heating and Cooling Handbook, McGraw-Hill, New York, 2002.

2. H. Feustel, C. Stetiu, Hydronic radiant cooling—preliminary assessment, Energy and Buildings 22 (1995) 193205.

3. Luis Perez-Lombarda Jose Ortiz, Juan F. Coronel, Ismael R. Maestre. A review of HVAC systems requirements in building energy regulations, Energy and Buildings 43, 255-268 (2011).

4. Corina Stetiu Helmut E. Feustel, "Hydronic radiant cooling - preliminary assessment," Energy and Buildings, vol. 22, no. 3, pp. 193-205, 1995.

5. J.v.d. Kooi, H.v.d. Ree J. Niu, "Energy saving possibilities with cooled-ceiling systems," Energy and Buildings, vol. 23, pp. 147-158, 1995.

6. Janita Y. C. Leung Sam C. M. Hui, "Thermal comfort and energy performance of chilled ceiling systems," in In Proceedings of the Fujian-Hong Kong Joint Symposium, Fuzhou, China, 29-30 June 2012, pp. 36-48.

7. T. Imanari, T. Omori. and K. Bogaki. Thermal comfort and energy consumption of the radiant ceiling panel system, comparison with the conventional all-air system, Energy and Buildings 30(2), 167-175 (1999).

8. Clemens Felsmann, Doreen E. Kalz, Sebastian Herkel Gregor P. Henze, "Primary energy and comfort performance of ventilation assisted thermo-active building systems in continental climates," Energy and Buildings, vol. 40, no. 2, pp. 99-111, 2008.

9. Corina Stetiu, "Energy and peak power savings potential of radiant cooling systems in US commercial buildings," Enrgy and Buildings, vol. 30, pp. 127-138, 1999.

10. Agis M. Papadopoulos Simos Oxizidis, "Performance of radiant cooling surfaces with respect to energy consumption and thermal comfort," Energy and Buildings, vol. 57, pp. 199-209, 2013.

11. L.Z. Zhang, H G. Juo J.L. Niu, "Energy Saving Potential of Chilled Ceiling combined with Dessicant Cooling in Hot and Humid Climates," Energy and Buildings, vol. 34, pp. 487-495, 2002.

12. Franc Sodec, "Economic viability of cooling ceiling systems," Energy and Buildings, vol. 30, pp. 195-201, 1999.

13. L.Z. Zhang, "Energy performance of independent air dehumidification systems with energy recovery measures," Energy, vol. 31, pp. 1228-1242, 2006. 
14. Taeyeon Kim, Suwon Song, Suckho Hwang, Seung-Bok Leigh Doosam Song, "Performance evaluation of a radiant floor cooling system integrated with dehumidified ventilation," Applied Thermal Engineering, vol. 28, pp. 1299-1311, 2008.

15. Z. Tian and James A. Love. Application of radiant cooling in different climate: assessment of office building through simulation, Eleventh International IBPSA Conference, Glasgow, Scotland , July 27-30, 2220-2227, 2009.

16. Esmail Saber, Rupesh Iyengar, Matthias Mast, Forrest Meggers, Kwok Wai Tham, Hansjürg Leibundgut. Thermal comfort and IAQ analysis of a decentralized DOAS system coupled with radiant cooling for the tropics. Buildings and Environment, in press (2014).

17. C. L. Conroy, S. A. Mumma. Ceiling radiant cooling panels as a viable distributed parallel sensible cooling technology integrated with DOAS, ASHRAE Transactions 107, Part 1 (2005).

18. ISO, ISO-11855. Building Environment Design—Design, Dimensioning, Installation and Control of Embedded Radiant Heating and Cooling Systems, International Organization for Standardization, 2012.

19. ASHRAE, ANSI/ASHRAE 138-2009. Method of Testing for Rating Ceiling Panels for Sensible Heating and Cooling, American Society of Heating, Refrigerating and Air-Conditioning Engineers, Inc., Altanta, 2009.

20. CEN, EN15377. Heating Systems in Buildings-Design of Embedded Water-Based Surface Heating and Cooling Systems, 2008.

21. Leon R. Glicksman Gang Tan, "Application of integrating multi-zone model with CFD simulation to natural ventilation prediction," Energy and Buildings, pp. 1409-1057, 2007.

22. EnergyPlus 2011. EnergyPlus (energy simulation software and supplemental documentation), www.energyplus.gov, US Department of Energy, 2011.

23. ANSYS FLUENT. ANSYS Fluent (Simulation Driven Product Management and FLUENT Documentation), Www.ansys.com.

24. Energy Conservation Building Code User Guide ISBN No. 978-81-909025-3-3, July 2009

25. ASHRAE Standard 55-2004, Thermal Environmental Conditions for Human Occupancy, American Society of Heating, Refrigerating and Air-Conditioning Engineers, Inc., Altanta

26. Michael Deru Kristin Field, Daniel Studer, Kyle Benne, Brent Griffith, Paul Torcellini, Bing Liu, Mark Halverson, Dave Winiarski, Michael Rosenberg, Mehry Yazdanian, Joe Huang. US Department of Energy 
Commercial Reference Building Models of the National Building Stock, National Renewable Energy Laboratory, 2011.

27. I. Nexant. M \& V Guidelines: Measurement and Verification for Federal Energy Projects (April), US Department of Energy, 2008.

28. AWBI H. B., Ventilation of Buildings.: E\&FN Spon, 1991.

29. Launder B.E. and Spalding D.B., Mathematical models of turbulence.: Academic Press, 1974.

30. ANSI/ASHRAE Standard 62.1-2004, Ventilation for Acceptable Indoor Air Quality.

31. J. E. Braun. Reducing energy costs and peak electrical demand through optimal control of building thermal storage, ASHRAE Transactions, 876-888 (1990).

32. R. A. Meierhans and B.W. Olesen. Betonkernaktivierung [Book], 3-00-004092-7, 1999.

33. ASHRAE Standard 90.1-2007, Energy Standard for Buildings Except Low Rise Residential Buildings, American Society of Heating, Refrigerating and Air-Conditioning Engineers, Inc., Altanta. 


\section{List of Figure Captions}

Figure 1: Methodology for Case Study

Figure 2: System Configuration

Figure 3: Radiant ceiling cooling system

Figure 4: Radiant floor cooling system

Figure 5: Comparison of Simulated and Measured Energy

Figure 6: Schematic of Conventional Case

Figure 7: CFD Drawing of Building (a) Drawing of Building, (b) Meshed Drawing of building

Figure 8: Temperature Variance (Running Case)

Figure 9: Temperature Variance (Conventional Case)

Figure 10: Schematic of Radiant System with DOAS

Figure 11: Energy savings for Running Case over Conventional Case

Figure 12: Energy Saving in Advance Case over Conventional Case

Figure 13: Annual Energy Consumption of all Cases

Figure 14: Spatial temperature Variance for Running Case \& Conventional Case

Figure 15: Average air temperature distribution

Figure 15: Energy Saving Comparison for Different Control cases 